\title{
Fundamentos da Cultura Portuguesa DA EXPANSÃO
}

\author{
Luís Filipe Barreto \\ Universidade de Lisboa \\ “...pera lhe escrever tudo é necessário que o mar \\ fosse tinta e o céu papel...
}

Fernão Mendes Pinto, 1555

\section{I}

A cultura discursiva do Renascimento Português resulta de três grandes dinamismos: o Escolástico, o Humanista e o da Expansão/Descobrimentos.

Esta trilogia é um sistema de porosidades e de correlações múltiplas mas é, ao mesmo tempo, um universo tridimensional de diferenças e de oposições.

A Escolástica e o Humanismo constituem, para utilizarmos uma expressão de Silva Dias ${ }^{1}$, hegemonias culturais. São hegemonias em concorrência pelo domínio dos centros de poder do tecido sociocultural através de estratégias de confronto e de diálogo, de exclusão e de integração. ${ }^{2}$

O confronto e a exclusão surgem em casos como, por exemplo, a Inquisição e a Censura da cultura discursiva. Censuras preventiva e repressiva que se abatem sobre impressos e manuscritos do programa humanista mas também da cultura popular escrita (literatura de cordel/autos) e da cultura da expansão a partir do programa cultural escolástico.

1 J.S. Silva Dias - Camões no Portugal de Quinhentos, Lisboa, ICALP, 1981, pg. 13-21.

2 Veja-se I.S.Revah - La Censure Inquisitoriale Portugaise au XVI Siècle, Lisboa. IAC, 1960. 
Confronto e exclusão na vida do Colégio das Artes, entre 1548 com a sua criação e entrega pela Coroa aos humanistas e 1555 com a passagem do Colégio para a Companhia de Jesus que testemunha a vitória institucional da Escolástica sobre o Humanismo³ ${ }^{3}$.

Estratégia também de diálogo e de integração como vemos no programa cultural da Companhia de Jesus e na sua Escolástica Conimbricense que em Coimbra e Évora usa a metodologia filológica e crítica dos humanistas como instrumento de melhor e de maior competência do programa cultural Aristotélico-Cristão/Tomista.

A tela cultural da expansão é, na época, claramente subalterna, existindo a partir de estratégias por entre e em confluência com as hegemonias. O universo cultural da expansão apresenta no entanto fronteiras e limites múltiplos e difusos, o que faz com que desde as culturas material e artística até às culturas popular e erudita encontremos elementos da sua forte presença.

Na verdade, a expansão marítima envolve a Coroa, a Igreja e a sociedade em geral. Por isso o seu universo cultural encontra-se mais ou menos presente em todos os planos e lugares da cultura e da sociedade portuguesas, muito em especial nos núcleos de portugueses em diáspora pelo mundo extra-europeu e também na Europa. Esta profunda dispersão, no para além de Portugal, concede à Cultura da Expansão margens únicas de liberdade, distância espacial e temporal únicas frente ao palco do controle e da repressão culturais.

As classificações de hegemónico e subalterno assentam em índices que permitem formar uma hierarquia de pesos culturais. Índices que levam em conta a posição do Estado e da Igreja frente aos programas culturais em jogo. Tomam também em conta a força editorial e o poder de e no ensino, a distribuição e o poder dos quadros culturais de cada uma das culturas bem como a capacidade de controle ou mesmo de repressão da concorrência cultural.

Estes índices mostram a Escolástica, a cultura clerical oficial, como a hegemonia triunfante. A estrutura cultural capaz de impor o seu programa e de derrotar pelo silenciamento, ou pela incorporação, a concorrência diluindo as alternativas culturais.

O Humanismo, a cultura laicizante dos humanitorae litterae, surge no Renascimento Português como a hegemonia institucionalmente derrotada. O programa humanista é, ao longo dos anos de 1540-1560, neutralizado ou integrado pela Escolástica. Apresenta contudo, ao longo da segunda metade de Quinhentos, de uma forma latente, um peso bem maior do que o apenas transmitido pelos índices institucionais patentes.

3 Veja-se Mário Brandão - O Colégio das Artes, Coimbra. I. Universidade, 1924-1933, 2 vols. e a Inquisição e os Professores do Colégio das Artes, Coimbra, I. Universidade, 1948-1969, 2 vols. 
A Escolástica e o Humanismo, as hegemonias culturais, são programas homogéneos. Na Escolástica, hegemonia triunfante, surge um bem maior grau de homogeneidade que no Humanismo, a hegemonia institucionalmente vencida. O grau de homogenidade está na razão directa da força de identidade cultural frente aos outros programas e por conseguinte no poder de fronteira e de fecho frente ao exterior. A Escolástica apresenta uma dimensão mais sistemática e fechada que o Humanismo e ambas as hegemonias quando comparadas com a cultura subalterna da expansão apresentam uma mais forte identidade e fronteira o que significa também uma menor abertura e recepção às diferentes culturas.

A Cultura da Expansão é a este nível um universo aberto com fronteiras em paradoxal tensão de afinidade e de diferença frente à Escolástica e o Humanismo. Esta quase não identidade ou alta heterogeneidade e abertura são índices de uma condição cultural subalterna. Heterogeneidade e abertura não apenas aos dinamismos culturais europeus do Renascimento mas também ‘às formas culturais exteriores à Europa, em especial às da Ásia, como mais à frente veremos, no peso das marinharias e cartografias chinesa e árabe ou nos casos do budismo Chen e do hinduismo.

A condição cultural subalterna da Cultura da Expansão manifesta-se nesta frágil identidade bem como na falta de sistematicidade do seu programa cultural. Características bem diferentes das consistentes classificativas, dos saberes e dos valores que vemos nos manuais dos Conimbricenses ou nas Orações de Sapiência dos Humanistas.

Índices da condição subalterna da Cultura da Expansão são ainda as ausências de um corpo e vocabulário conceitual teórico próprio, a falta de peso editorial e o seu reduzido impacte nos programas e instituições oficiais de ensino dominados pela Escolástica e por um Humanismo acomodado.

Estas limitações na identidade e na homogeneidade obrigam a Cultura da Expansão a ser a formação cultural mais aberta do Renascimento Português, aquela que mais necessita de empréstimos culturais a partir da Escolástica e do Humanismo.

A Escolástica é sem dúvida a cultura menos receptiva e aberta aos pontos de vista e aos reportórios das outras culturas, a que menor número de correlações estabelece com o exterior do seu programa cultural.

Os encontros que a Escolástica promove com o universo cultural da Expansão são pontuais e de natureza essencialmente factual/informativa. Os momentos mais relevantes desse encontro surgem a propósito do "Regis Lusitanae Nautae"4 no Physicis Compendium, 1520, de Pedro

\footnotetext{
4 Pedro Margalho Physices Compendium, Salamanca, 1520, Fol.VIIr. Veja-se Luís Ribeiro Soares - Pedro Margalho, Lisboa, I. Nacional, 2001 e A.A. Coxito - Lógica, Semântica e Conhecimento na Escolástica Peninsular Pré-Renascentista., Coimbra, I. Universidade, 1981.
} 
Margalho, quando se discute a proporção igual do mar e da terra no Globo 5 .

Para além deste momento na Escolástica de transição, vemos a Cultura da Expansão como suporte informativo de actualização em alguns casos da Nova Escolástica, como por exemplo nos Comentarii in Libros Meteorum, 1593, de Manuel de Góis S.J., a propósito do nome Mar Vermelho, da habitabilidade dos trópicos e da quarta nova parte do mundo ${ }^{6} \mathrm{e}$ nos exercícios dos professores da Universidade de Évora como os de Fernão Rebelo S.J., a propósito do direito das gentes e da escravatura.

O Humanismo apresenta frente ao universo cultural da expansão uma abertura e um encontro bem mais fortes que os da Escolástica.

Em vários temas e problemas, em especial de natureza doutrinária ideológica mas também nos campos das racionalidades médica e geográfica, as fronteiras culturais do Humanismo e da Cultura da Expansão, cruzam-se regularmente ao longo do século XVI

A Expansão surge para a maioria dos humanistas como arsenal de novidades, como novo quadro de dados e de diferenças que possibilita ao studia humanitatis fortes elementos de crítica e de prova frente à herança medieval através de tópicos como a nova idade do mundo ou a pluralidade das realidades. Não admira pois que humanistas e cidades pólos do Humanismo sejam, ao longo de Quinhentos, dos principais centros de recolha e de difusão do universo cultural da expansão marítima e mercantil dos portugueses. E que exista uma abundante literatura latinista dos humanistas em torno da expansão?

A Cultura da Expansão apresenta constantes pedidos de apoio e usos de empréstimo à Escolástica e ao Humanismo. Antes de mais porque muitos dos produtores da geografia descritiva e antropológica e da doutrina-ideologia da Cultura da Expansão são, também, membros das Culturas Escolástica e Humanista, com uma formação própria a essas hegemonias culturais.

Mas a questão é bem mais complexa e não se resume à tipologia dos

5 Sobre este problema, veja-se W.L. Randles - De la Terre Plate au Globe Terrestre Une Mutation Epistémologique Rapide (1480-1520), Paris, A. Colin, 1980 (trad. Port., Lisboa, Gradiva, 1990).

6 Manuel de Góis - Commentarii Collegi Conimbricensis in Libros Meteorum Aristotelis Stagiritae, Lisboa, 1593, pg. 77-78 e 104-105. Veja-se e A.A. Coxito - A Teoria das "Ciências" no Curso Filosófico Conimbricense, Coimbra, I. Universidade,1977 e J.S.Silva Dias - O Cânone Filosófico Conimbricense (1592-1606), Sep. Cultura História e Filosofia, vol. IV, Lisboa, 1985.

7 Veja-se Luís de Matos - L’Expansion Portugaise dans la Littérature Latine de la Renaissance, Lisboa, F.C.Gulbenkian, 1991. Sobre Humanismo e Expansão em Portugal, veja-se R.Hooykaas The Impact of the Voyages of Discovery on Portuguese Humanist Literature Coimbra,1970 (trad. port., Gradiva, 1983). 
quadros culturais. O eco informativo do universo da Expansão (pontual e limítado na Escolástica mas sistemático e profundo no Humanismo) é tão só a face de uma moeda. A outra face mostra o peso dos conceitos e dos valores da Escolástica e do Humanismo na Cultura da Expansão.

O universo cultural da Expansão existe graças também aos fundamentos teóricos e metodológicos que recebe da escolástica aristotélico-tomista e do humanismo em especial dos programas humanistas regulados pelo aristotelismo naturalista e pelo humanismo cívico cristão.

O universo cultural da Expansão, sobretudo devido à atenção cultural e editorial dos humanistas, produz um impacte de novidade e de algum interesse nos outros programas culturais, em especial no Humanista. Mas, ao mesmo tempo, é uma tela cultural que troca informação por formação e formulação Escolástica e Humanista.

Estes sistemas de trocas entre os três componentes chave do Renascimento Português tem a ver com o princípio nuclear de cada uma das culturas. A Escolástica e a Humanista são culturas de orientação sapiencial-doutrinária enquanto que a cultura da Expansão apresenta uma orientação científico-objectiva.

A Escolástica produz um doutrinário sapiencial determinado por um saber religioso, por toda uma visão transcendental do mundo e da vida orientada para um metarreal (Deus). O Humanismo, cultura laicizante em concorrência com a cultura clerical oficial, apresenta um doutrinário-sapiencial vocacionado para um ser/saber humanos. Trata-se de uma visão tão imanente quanto transcendente do mundo e da vida, orientada para a compreensão de uma realidade fenomenal originariamente criação transcendental (o Homem).

A Cultura da Expansão, em especial nas zonas nucleares da marinharia técnico-prática e da cientificidade teórico-crítica, encontra a sua ideia condutora no saber regulado pelo ideal de verdade objectiva.

A Cultura da Expansão tem como horizonte metódico a ideia de Ordem. A construção de regularidades e de normas preside à busca dos problemas técnicos e objectivos bem como à formulação de hipóteses teóricas e de soluções práticas.

A Escolástica e o Humanismo encontram na Significação o essencial do seu horizonte metódico. Na Escolástica esta busca dá-se em torno do sentido transcendental do ser e no Humanismo a propósito da valoração do Humano.

No Renascimento, os horizontes metódicos da Ordem e da Significação tendem tanto à separação quanto ao sincretismo e à fusão. Também por isso, na Cultura da Expansão encontramos campos em que o horizonte metódico da Significação domina ou esbate o da Ordem, como vemos no caso do periférico campo da doutrina-ideologia e em algumas obras do campo geográfico-antropológico. 
Não é possível traçar fronteiras duras no clima épocal renascentista e as fronteiras unem pelo menos tanto quanto separam, pois “...era ainda $o$ tempo, onde no campo do conceito, nenhum viajante era desconhecido..." 8 .

Existe a impossibilidade de oposição total entre Escolástica, Humanismo e Cultura da Expansão, pois, por exemplo, para os três programas temos uma ontologia comum regulada pelo paradigma orgânico de um Aristotelismo cristão. Mas existe também a possibilidade de diferenciar a trilogia discursiva do Renascimento Português e de ver o universo cultural da Expansão com uma certa lógica própria e diferencial frente aos caminhos da Escolástica e do Humanismo.

\section{II}

A cultura portuguesa da expansão marítima assenta em quatro grandes campos: O técnico-prático da marinharia, o teórico-crítico da cientificidade, o da geografia descritiva e antropológica e o da doutrina-valoração ideológica?

Cada um destes campos tem uma individualidade e identidade próprias, mas tem também, ao mesmo tempo, uma abertura de fronteiras que permite uma constante circulação e contaminação de temas e de problemas entre todos os campos.

A doutrina-ideologia é tanto um espaço discursivo da expansão marítima quanto um espaço das culturas humanista e escolástica sobre o fenómeno da diáspora surgindo pois como periferia e lugar de encontro por excelência da cultura portuguesa da expansão com a cultura portuguesa sobre a expansão.

Os quatro campos culturais sobretudo os três primeiros, apresentam determinadas características sociodinâmicas. Ao contrário das culturas escolástica e humanista onde predomina ou tem destacada presença o latim, a cultura discursiva da expansão é maioritariamente pensada e escrita em língua portuguesa.

Este domínio esmagador da língua portuguesa, com um papel muito

8 J. T. Desanti - La Philosophie Silencieuse ou Critique des Philosophies de la Science, Paris, Seuil, 1975, pg. 7

9 Sobre este modelo da Cultura Portuguesa da Expansão/Descobrimentos, veja-se Luís Filipe Barreto - Portugal Pioneiro do Diálogo Norte Sul: Para um Modelo da Cultura dos Descobrimentos Portugueses, Lisboa, I. Nacional, 1988, pg. 10 a 49;: Os Descobrimentos e a Ordem do Saber: Uma análise Sociocultural, Lisboa, Gradiva, 1987, pg. 9 a 54 e Portugal Mensageiro do Mundo Renascentista - Problemas da Cultura dos Descobrimentos Portugueses, Lisboa, Quetzal, 1989, pg. 15 a 46. Sobre o horizonte cultural da Expansão em geral, veja-se J.S.Silva Dias - Os Descobrimentos e a Problemática Cultural do Século XVI, Coimbra, I. Universidade, 1973. 
residual e pontual do latim, significa que a maioria dos quadros produtores e consumidores da cultura discursiva da expansão tem uma formação não universitária. O latim é a língua da formação, produção e consumo das universidades e das culturas institucionalmente hegemónicas, casos da Escolástica e do Humanismo.

A maioria dos quadros culturais da expansão tem uma formação escolar básica de saber ler e contar bem com uma aprendizagem prática e especializada nas escolas da vida marítima e mercantil.

Apenas uma minoria ligada à nobreza, nalguns casos mesmo alta nobreza, como vemos em Duarte Pacheco Pereira, D. João de Castro, Pêro Lopes de Sousa, ou a círculos urbanos burgueses tem uma formação cultural de Corte ou mesmo universitária que é frequente entre os missionários jesuítas produtores de geografia descritiva e antropológica.

A maioria dos produtores e consumidores da cultura da expansão tem uma origem social não nobre. A criação em português de saberes especializados regulados pelos ideais de verdade e de utilidade e de doutrinas em busca da crítica e da eficácia institucional são sinais de um alargamento da base de sustentação social da cultura letrada e da literacia a novos grupos em ascensão no tecido social português.

A cultura discursiva da expansão apresenta também um largo predomínio do manuscrito sobre o impresso. Cultura especializada e prática que muitas vezes encontra a sua comunidade de leitura e conhecimento através de um muito reduzido número de cópias não necessitando das poucas centenas de exemplares impressos.

A cultura da expansão é sobretudo um saber fazer e um saber poder. Muita da utilidade e aplicação destes conhecimentos náuticos, cartográficos, geográficos e antropológicos reside no seu desconhecimento por parte de outros concorrentes marítimo-mercantis, em especial europeus (italianos, castelhanos, ingleses e holandeses).

O controle da circulação da informação em especial por parte do Estado e dos círculos mercantis é uma das razões chave para o predomínio do manuscrito sobre o impresso que é tanto mais intenso quanto mais se conjugarem os valores da verdade e da utilidade, ou seja, do conhecimento preciso e precioso. Por isso, não existe em Portugal impressão de livros de marinharia ou de cartografia náutica e a geografia descritiva e antropológica alcança percentagens de cerca de $90 \%$ de manuscrito.

O largo predomínio da controlada circulação manuscrita de um reduzido número de cópias em vez de uma aberta circulação impressa de centenas de exemplares é um dos sinais de forte presença do Estado na cultura da expansão. A Coroa de Lisboa mas também os centros de poder local nos litorais de África, Brasil e Ásia funcionam com os seus quadros e pólos de atracção de mercadores e de colonos como núcleos maiores de produção e de consumo da cultura da expansão. 
Para além do Estado, à medida que avançamos nos finais de Quinhentos, a Igreja missionária, em especial os Jesuítas surgem como um outro polo relevante de produção e de organização culturais sobretudo no domínio da geografia descritiva e antropológica.

A Cultura da Expansão Portuguesa no Mundo, em especial nos seus três primeiros campos nucleares e saber preciso e precioso sobre os mares e os mundos extra-europeus é maioritariamente manuscrita mas sofre a concorrência de outros pólos de informação impressa na Europa do século XVI.

O esforço da Coroa portuguesa para controlar a informação por via da cópia manuscrita sofre a concorrência doutros poderes europeus, políticos, económicos, religiosos, de modo a retirar esses saberes dos círculos restritos de divulgação.

O impacte da cultura da expansão portuguesa na Europa resulta desta concorrência entre diferentes comunidades e pólos de saber e de poder. Resulta também da circulação de quadros portugueses de cartografia, náutica, medicina, pela Europa de Quinhentos. Uma cultura portuguesa maioritariamente manuscrita atinge um alto impacto cultural europeu através da cópia, tradução e edição de numerosos materiais em línguas italiana, espanhola, holandesa, inglesa, francesa, alemã e em latim.

\section{III}

O impacte europeu da Cultura Portuguesa da Expansão marítimo-mercantil pelos mares e litorais do Atlântico, Índico e Pacífico, dá-se sobretudo através de seis grandes vias ${ }^{10}$.

A primeira dessas vias assenta na recolha, tradução e edição de manuscritos portugueses. Existem dois grandes pólos de recolha, tradução e edição. Nos inícios do século XVI, mesmo até meados de Quinhentos temos o domínio de pólo italiano e de centros editoriais como Veneza, Milão, Florença, Roma, como vemos, por exemplo, nas grandes colecções de geografia descritiva de F. Montalboldo - Paesi novamente retrovati et novo mundo ..., Vicenza, 1509 e de Giovanni Baptista Ramusio - Delle Navigationi et Viaggi, Veneza, 1550

10 Estamos longe de ter um conhecimento preciso sobre o impacte da Cultura Portuguesa da Expansão na Cultura Europeia dos Séculos XVI e XVII. Apenas dos meados de Quatrocentos até 1521 temos um exaustivo levantamento em A.A. Banha de Andrade Mundos Novos do Mundo: Panorama da Difusão pela Europa, de Notícias dos Descobrimentos Geográficos Portugueses, Lisboa, J.I.Ultramar, 1972, 2 vols. Até meados de Quinhentos é de grande utilidade Francisco Leite de Faria - Estudos Bibliográficos sobre Damião de Góis e a Sua Época, Lisboa, F. Calouste Gulkbenkian, 1991. 
A partir destas edições surgem várias outras reedições totais ou parciais, como no caso dos Paesi de F. Montalboldo que, ao longo de Quinhentos, tem reedição italiana em Milão, 1508, 1512 e 1519 e em Veneza, 1517 e 1522, bem como tradução latina em Milão, 1508 Itinerariu Portugallesiu, reeditada no Novus Orbis, Basileia, 1532 e em Paris, no mesmo ano, com duas tiragens e de novo em Basileia em 1537. Em Nuremberga, em 1508, surgem duas traduções alemãs e nova edição alemã em Estrasburgo, 1534, a partir da tradução latina, bem como sete edições francesas em Paris, a partir dos anos de 1516 ou 1517.

A grande atenção editorial italiana à Cultura da Expansão Portuguesa assenta na concorrência entre as Rotas euroasiáticas do Levante e do Cabo, concorrência mercantil que é também concorrência informativa. Passa ainda pelos missionários jesuítas e pela Igreja católica de Roma, como vemos por exemplo nas colecções de Cartas e de Geografias-Antropologias Descritivas organizadas pelos missionários jesuítas, como os Diversi Avisi Particolari dall'Indie, Veneza, 1559 ou os Nuovi Avisi delle Indie di Portogallo, Veneza, 1563.

Uma vez mais, a edição italiana vai originar outras reedições e traduções como vemos com o manuscrito Tratado da China de Galeote Pereira, de cerca de 1555, com edição no vol. IV dos Nuovi Avisi, Veneza, 1563 e tradução e edição inglesas em Londres, 1577 na colecção de R. Wills History of Travayle in the West and East Indies.

O segundo grande pólo de recolha, tradução e edição de manuscritos portugueses da Cultura da Expansão é o holandês, a partir dos finais do século XVI, em centros como Antuérpia, Amesterdão, Leida.

Ao contrário do pólo italiano que fixou a atenção editorial na geografia descritiva e antropológica e na historiografia, o pólo holandês privilegia a componente técnico-científica da Cultura da Expansão Portuguesa editando principalmente cartografia e roteirística.

Edição de cartografia náutica portuguesa em colecções como a de A. Ortelis -Theatrum Orbis Terrarum, Antuérpia, 1584 e a de L.J. Waghenaer-Tressor der Zeevaert, Leida, 1592. A edição de Antuérpia, 1584, traz a primeira carta particular europeia impressa da China, a Carta da China de Jorge Luis Barbuda, c. 1575 e na edição do Theatrum Orbis Terrarum, de Antuérpia, 1595, surge a Carta do Japão, de Luís Teixeira, c. 1591.

A grande colecção impressa de Roteiros Oceânicos Portugueses surge em Amesterdão, 1595. O Reysghereschrifit van de Navigatien der Portugaloysers in Orienten de J. Huygan van Linschoten contém Roteiros da Rota do Cabo, como por exemplo, o Roteiro de Lisboa à Índia, de Diogo Afonso, c. 1535 e Roteiros locais, sobretudo dos mares da Ásia do Sueste e da Ásia Oriental, como o anónimo Roteiro do Porto de Macau para o Japão, de cerca de 1560-1570. 
Para além destas colecções e destes pólos editoriais chave existe um número imenso de edições particulares e pontuais de obras portuguesas manuscritas. O Roteiro do Mar Roxo, 1541, de D. João de Castro, surge impresso em versão sintética, em Londres, 1625, na edição de Samuel Purchas - Harluytus Posthumus, vol. IV. Nesse mesmo volume são também editados pela primeira vez e em inglês, os Tratados do Clima e Terra do Brasil e Do Princípio e Origem dos Índios do Brasil e de seus costumes e cerimómias, de 1584, do Jesuíta Fernão Cardim.

Numerosa cartografia náutica manuscrita portuguesa surge impressa como vemos por exemplo nos casos de Cartas de Pedro Lemos e de Luís Teixeira usadas em Nova et accurata Totis Orbis Terrarum, Amesterdão, 1599, de Hendrick van Langreen.

Edições italianas, latinas, holandesas, inglesas, mas também castelhanas e com redições e traduções em outras línguas. Edição espanhola de manuscritos portugueses que encontramos em Sevilha, 1535, com o Tratado del Sphera y del Arte de Marear de Francisco Faleiro, em Burgos, 1578, com o Tratado de las Drogas y Medicinas de las Indias Orientales de Cristóvão da Costa, em Antuérpia, 1610, com as Relaciones de Pedro Teixeira ou em Roma, 1649, com o Itinerario de las Missiones del India Oriental de Sebastião Manrique. Apenas alguns casos da constante atenção editorial espanhola que ao contrário dos pólos italiano e holandês apresenta uma alta variedade de matérias que vai desde a náutica astronómica até à botânica médica passando pela geografia e antropologia descritivas.

Tradução de materiais vários e em diferentes línguas com uma característica de rapidez de edição de obras manuscritas produzidas em Lisboa, Goa, Malaca, Mares da China ou Brasil que passados poucos anos, 4, 7, 9, 12, são os intervalos frequentes, surgem impressas em Itália ou Espanha, na Holanda ou em Inglaterra.

A segunda via de larga difusão europeia da Cultura da Expansão portuguesa passa pela tradução e edição em várias outras línguas europeias de obras impressas em português.

Uma vez mais vamos tão só dar alguns casos que julgamos mais representativos do impacte europeu. Em Lisboa, 1540, é editada a Verdadeira Informação da Terra do Preste João, de Francisco Álvares ${ }^{11}$. A edição italiana surge em Veneza, 1550, no Primo Volume delle Navigationi et Viaggi de J.B. Ramúsio. Na época a obra de Ramúsio é reeditada em Veneza, em 1554, 1563, 1588, 1606 e 1613. As traduções espanholas de Francisco Álvares surgem em Antuérpia, 1557, Saragoça, 1561 e Toledo, 1588. Em Lião, em 1556 surge a edição francesa e as edições

11 Veja-se A.A. Banha de Andrade - Francisco Álvares e o Êxito Europeu da Verdaeira Informação Sobre a Etiópia, Lisboa, CECA, 1982. 
alemãs em Eisleban são de 1566, 1567, 1572, 1573, 1576 e 1581. A edição inglesa é de Londres, 1625.

Em Goa, 1563, são editados os Colóquios dos Simples e Drogas da Índia, de Garcia de Orta, a mais importante obra portuguesa da farmacopeia renascentista de origem asiática. Em Antuérpia, 1563, surge a primeira de muitas traduções e edições parciais latinas por C. Ecluse. Seguem-se em Antuérpia as edições latinas de 1567, 1574, 1571, 1593, 1605 e anotações ao livro em 1582. De 1593 é também a edição latina de Frankfurt ${ }^{12}$.

A primeira edição italiana é de Veneza, 1576, seguindo-se na mesma cidade duas edições em 1582, duas em 1589, duas em 1597 e uma em 1605. Em Lião, em 1602, surge a edição francesa.

Para além das descritivas geográfico-antropológicas encontramos a tradução de impressos portugueses sobretudo nas áreas da historiografia e da doutrina da Expansão.

As duas primeiras Décadas da Ásia de João de Barros ${ }^{13}$, impressas em Lisboa nos anos de 1552 e 1553 surgem em edição italiana em Veneza, 1565 e 1572 . As partes geográficas da obra de João de Barros surgem também em italiano, em Veneza, 1563.

A História do Descobrimento e Conquista da Índia pelos Portugueses de Fernão Lopes de Castanheda ${ }^{14}$, editada em Coimbra, 1551-1561, surge em italiano em Veneza, 1578. E a partir destas edições italianas de João de Barros e Castanheda, seguem-se outras traduções e edições na Europa.

A obra do jesuíta Duarte de Sande -De Missione Legatorum, Macau, 1590, é parcialmente traduzida e editada em inglês, em Londres, 1599, com o título de Excellent Treatise of the Kingdom of China.

A Peregrinação de Fernão Mendes Pinto, escrita provavelmente entre os anos de 1568 e 1578 é impressa pela primeira vez em Lisboa, 1614. A tradução espanhola surge em Madrid, 1620, tendo mais cinco edições na Espanha do século XVII. A primeira edição francesa é de Paris, 1628 e em 1645 volta a ser editada. Na restante Europa sucedem-se as edições parciais. Londres, 1625 e mais três edições inglesas em Seiscentos. Em Amesterdão, 1662, surge a edição holandesa e em 1653 e 1656 novas

12 Veja-se, Conde de Ficalho - Garcia de Orta e o Seu Tempo, Lisboa, I. Nacional, 1886, pg. 367 a 392.

13 Sobre João de Barros, veja-se, A.A. Banha de Andrade - João de Barros Historiador do Renascimento Português de Quinhentos, Lisboa, APH, 1980; C.R. Boxer - João de Barros Portuguese Humanist and Historian of Asia, N. Delhi, C.P,C, 1981 e A. Borges Coelho - Tudo é Mercadoria: Sobre o Percurso e a obra de João de Barros, Lisboa, Caminho, 1992 e João de Barros: Vida e Obra, Lisboa, C.D.P, 1997.

14 Veja-se, Ana Paula Menino Avelar - Fernão Lopes de Castanheda: Historiador dos Portugueses na Índia ou Crónica do governo de Nuno da Cunha?, Lisboa, Cosmos, 1997. 
edições. Também em Amesterdão, 1671, é impressa a primeira edição alemã havendo durante o século XVII mais quatro edições nesta língua ${ }^{15}$.

A terceira via passa pelos quadros portugueses ao serviço de outras coroas europeias e das suas obras manuscritas e impressas. Uma diáspora europeia sobretudo de quadros práticos e técnicos de náutica e de cartografia (pilotos, mestres, cartógrafos, oficiais de construção naval) bem difícil de acompanhar e dimensionar.

Apenas os nomes mais sonantes da marinharia correspondem, no século XVI, a "60 ao serviço de Espanha, 25 ao serviço de França e 6 ao serviço de Inglaterra" 16 . Na Espanha, França e Inglaterra dos séculos XVI e dos inícios do XVII, a comunidade de técnicos e de cientistas estrangeiros mais numerosa na náutica, cartografia e construção naval é a portuguesa $^{17}$.

Entre os quadros portugueses ao serviço de Espanha destacam-se Francisco Faleiro e Cristovão da Costa já mencionados a propósito de edições em língua castelhana, mas também Diogo Ribeiro, cosmógrafo mor da Casa das Índias em Sevilha, a partir de 1523 ou o navegador e geógrafo Pedro Fernandes de Queiros (c.1565-1615), autor de várias obras manuscritas de náutica, nos anos de 1595 a 1610.

Manuscrita fica também a obra de João Afonso La Cosmographie avec L'Espere et le regime du Soleil et du Nord, de cerca de 1542 que reproduz, em francês, as tábuas do Regimento português editadas em Évora, 1516.

A quarta via é de certo modo uma paralela complementar da anterior, ou seja, os quadros da restante Europa ao serviço ou envolvidos na Expansão marítima e mercantil dos portugueses.

São sobretudo mercadores e missionários jesuítas com a hegemonia da comunidade italiana seguida da espanhola e de poucos holandeses, franceses, alemães, polacos, etc.

Quadros de informação preciosa e actualizada. Como vemos no caso de Girolamo Sernigi e das suas Cartas de Lisboa, de 10 de Julho e 29 de Agosto de 1499 sobre a primeira viagem de Vasco da Gama à Índia ${ }^{18}$.

15 Veja-se F. Leite de Faria - As muitas Edições da "Peregrinação" de Fernão Mendes Pinto, Lisboa, A.P.H., 1992.

16 A. Teixeira da Mota - A Evolução da Ciência Náutica Durante os Séculos XV-XVI na Cartografia Portuguesa da Época, Lisboa, A.C.L., 1961, pg. 11.

17 Sobre esta comunidade em Espanha, veja-se J.L.Lopez Pinero - Ciencia y Tecnica en la Sociedad Espanola de los Siglos XVI y XVII, Barcelona, Ariel, 1979 e para França, Luís de Matos - Les Portugais em France au XVI Siècle: Études et Documents, Coimbra, I. Universidade, 1952.

18 Veja-se Carmen Radulet - Os Descobrimentos Portugueses e a Itália, Lisboa, Vega, 1991 e Vasco da Gama, la Prima Circunnavigazioni dell'Africa 1497-1499, C. di Castello, Diabasis, 1999. 
Com o bolonhês Ludovido de Varthema e o Itinerário, Roma, 1510 ou o Florentino Giovanni da Empoli (1483-1517) e as suas Cartas de Lisboa e de Cochim para Florença, em 1514 e 1515, onde se dá conta da chegada dos portugueses ao litoral da China, logo em impresso de Florença, 1516 da segunda das Cartas ${ }^{19}$.

No plano da geografia descritiva dos mercadores a obra paradigmática de divulgação europeia da Expansão Portuguesa é o Itinerário, Amesterdão, 1596, de J. H. van Linschoten. Depois da primeira edição holandesa surge logo em 1598 a edição inglesa, em 1599, a latina, a alemã nos anos de 1598, 1599 e 1600 e a primeira edição francesa em Frankfurt, em 1610.

Do imenso mundo da internacional universitária latina que é a Companhia de Jesus, destaco a mero título de exemplo, apenas duas figuras com alta dimensão cultural no universo da Expansão Portuguesa.

O primeiro dicionário de chinês numa língua ocidental é o manuscrito Dicionário Português-Chinês ${ }^{20}$, nascido em Macau nos anos de 1580 a partir de uma equipe coordenada pelo jesuíta italiano Miguel Ruggiero (1543-1607). A primeira gramática portuguesa de tupi impressa em Coimbra, 1595, Arte de Grammatica da Lingoa mais usada na Costa do Brasil é da autoria do jesuíta espanhol José de Anchieta (1534-1597).

A quinta via de impacte europeu da Cultura Portuguesa da Expansão reside na recolha e na restrita circulação de manuscritos portugueses em círculos europeus de elite política, económica e cultural. Círculos humanistas do Centro Norte da Europa e de Itália que acumulam e/ou traduzem manuscritos portugueses como o da colecção de textos náutico-geográficos denominada Livro de Vaentim Fernandes, a cópia da carta-padrão denominada Planisfério Cantino, de 1502, o denominado Codex Bratislavensis com materiais sobre a Expansão Portuguesa de 1494 a 1519, a Ars Nautica, c.1570, de Fernando Oliveira, etc.

A sexta via, sem dúvida a mais frequente, mas também a mais difícil de historiar tem a ver com a informação oral-vivencial, com a circulação e colecção de peças e de coisas exóticas transmitidas à Europa pela Expansão Portuguesa.

Uma vez mais vamos tão só aflorar alguns casos. Nos anos de 1530 aparecem os primeiros jardins botânicos de plantas exóticas orientais (em

19 Veja-se Marco Spallanzani - Mercanti Fiorentini nell'Asia Portughese, Firenze, Scelte, 1997.

20 Sobre esta obra ainda inédita, Veja-se Paul Fu-Mien Yang - The Portugueses-Chinese Dictionary of Michele Ruggieri and Matteo Ricci: A Historical and Linguist Introduction, Taipe, A. Sinica, 1989 e Luís Filipe Barreto - Macao, an Inter Culture Border in the Ming Period in Ming Qingyanjiu, Nápoles, I. Orientale, 2000. Sobre os dicionarios português-chinês, veja-se João de Deus Ramos - Estudos Luso-Orientais, Lisboa, A.P.H., 1996, pg. 109-118. 
1528 a quinta da Bacalhoa de Brás de Albuquerque, em 1539 a da Penha Verde de D. João de Castro, as colecções de Amato Lusitano) e as primeiras colecções regulares europeias de livros e de raridades asiáticas e de além-mar. Lisboa, Antuérpia, Florença, Roma, são alguns dos lugares de constituição e de troca destas bibliotecas e colecções de exotismos e instrumentos.

Ao longo da segunda metade de Quinhentos são editadas recolhas de gravuras sobre os diferentes tipos de vestuário e de aspecto físico dos homens extra-europeus, uma espécie de iconografia das descritivas geográficas com os portugueses a serem o intermediário chave ${ }^{21}$.

Desde François Deserpz -Recueil de la Diversité des Habits ..., Paris, 1562, até Cesare Vecellio - Degli Habiti Antichi e moderni di diverse parte del mondo, Veneza, 1590, passando por entre outros, Abraham de Bruyan - Omnium poeme gentium imagines, Colónia, 1577 e Antuérpia, 1581, a iconografia europeia começa a criar um banco de dados relativamente amplo e seguro.

No caso da iconografia europeia sobre a Ásia, a ligação à intermediária dimensão cultural da Expansão Portuguesa é bastante manifesta, por exemplo, nas gravuras de 1595 de B.van Dentecum que acompanham as edições citadas de J.H.van Linschoten ou na obra de C. Vecellio de Veneza, 1590 que apresenta um dos daimios japoneses da embaixada de 1582 no Conselho de Veneza, em 1585 e alguns chineses copiados de imagens chinesas recebidas certamente em Itália, a partir de Macau.

\section{IV}

Agora vamos, de um modo breve, observar a paisagem interna de cada um dos campos começando pelo técnico-prático da marinharia. A marinharia, ou seja, o saber objectivo e útil directamente implicado com a navegação é um campo feito de náutica, cartografia e construção/arquitectura navais.

A astronomia náutica ${ }^{22}$ apresenta como tipos essenciais de obras, os

21 Veja-se Marília Santos Lopes - Portugal: Uma Fonte de Novos Dados - A Recepção dos Conhecimentos Portugueses sobre África nos Discursos Alemães dos Séculos XVI $e$ XVII in Mare Liberum, Lisboa, CNCDP, 1990, n. ${ }^{\circ}$ 1, pg. 205 a 308 e Coisas Maravilhosas até Agora Nunca Vistas, para uma Iconografia dos Descobrimentos, Lisboa, Quetzal, 1999.

22 Veja-se Luís de Albuquerque - Introdução à História dos Descobrimentos, Coimbra, Atlântida, 1962 e Curso de História da Náutica, Coimbra, Almedina, 1972; António Barbosa - Novos Subsídios para a História da Ciência Náutica Portuguesa da Época dos Descobrimentos, Porto, I.A.C., 1948; A. Fontoura da Costa - A Marinharia dos Descobrimentos, Lisboa, E.C.M.,1983; A. Teixeira da Mota - Os Regimentos do Cosmógrafo-Mor de 1559 a 1592 e as Origens do Ensino Náutico em Portugal, 
Livros de Marinharia ${ }^{23}$, os Roteiros ${ }^{24}$, os Diários de Navegação ${ }^{25}$ e os Guias Náuticos. São obras vocacionadas para a formação e a informação da navegação astronómica. Todas escritas em português e quase todas, na época, manuscritas. A excepção reside nos Guias Náuticos como os chamados de Munique e de Évora, impressos em Portugal, cerca de 1509 e 1516, que são obras de exposição didáctica das regras da astronomia com implicação à náutica ${ }^{26}$.

Os Roteiros, os Diários de Navegação e os Livros de Marinharia, ficam, na época, manuscritos em Portugal. São obras de informação revolucionária sobre as latitudes, os ventos, as marés, as correntes e as

Lisboa. A.Ciências, 1969 e O Regimento da Altura de Leste-Oeste de Rui Faleiro, Lisboa, E.C.M., 1986.

23 Os Livros de Marinharia são obras colectivas compostas por uma parte formativa e normativa, com regimentos para a determinação das latitudes e regras sobre a agulha de marear, e por uma parte informativa com Roteiros, oceânicos e de costa, e múltiplos dados práticos de pilotagem como singraduras, conhecenças, levantamentos de fundos, etc.

São obras colectivas e acumulativas em que os autores e as datas apresentadas correspondem ao nome de um dos relactores (redactor final ou maioritário) e á época provável em que findou a sua máxima actualização/utilização.

O quadro documental dos livros de marinharia inclui o de cerca de 1512-1513 de Francisco Rodrigues, os de meados do século XVI chamados de João de Lisboa, André Pires e Manuel Álvares, os de início da segunda metade de Quinhentos, ditos de Pêro Vaz Fragoso e de Bernardo Fernandes, o ainda inédito, de cerca de 1587, o de Gaspar Moreira dos inícios do século XVII e os de cerca de 1605-1607 e 1635, editados por Gabriel Pereira com o título de "Roteiros Portugueses da Viagem de Lisboa à Índia nos Séculos XVI e XVII, Lisboa, I. Nacional, 1898.

Sobre a natureza dos Livros de Marinharia, veja-se Luís de Albuquerque - Estudos de História, vol.V, Coimbra. I. Universidade, 1977.

24 Os Roteiros são traçados ideais das derrotas apurados processual e colectivamente, veja-se A. Teixeira da Mota - Evolução dos Roteiros Portugueses Durante o Século XVI, Lisboa, J.I.U., 1969, e S, Daveau - La Geographie dans les Roteiros Portugais du Xv au XVI siècles, Lisboa, C.E.G., 1988.

25 Diários de Navegação são textos de anotação, dia a dia, dos elementos náuticos mais relevantes da viagem. Descritivas da vivência concreta cada vez mais ricas e pormenorizadas à medida que avançamos nos finais de Quinhentos e nos inícios de Seiscentos. Desse quadro documental mais valioso destacam-se Diários de Navegação da Carreira da Índia nos anos de 1595, 1596, 1597, 1600 e 1603, ed. Quirino da Fonseca, Lisboa, A.C.L, 1938 e Viagens do Reino para a İndia e da Índia para o Reino (1608-1612), ed. H. Leitão, Lisboa, A.G.U., 1957-1958, 2 vols. Veja-se Joaquim Rebelo Vaz Monteiro - Uma Viagem Redonda da Carreira da Índia (1597-1598), Coimbra, I. Universidade, 1985.

${ }^{26}$ São os dois mais antigos Guias Náuticos sendo o segundo uma versão acrescentada e melhorada do primeiro. No essencial, são obras compostas pela exposição da determinação da latitude pela Polar, o "Regimento da Estrela do Norte", da determinação da latitude pela altura meridiana do Sol, o "Regimento da Declinação do Sol", de tábuas solares e da tradução portuguesa da Sphaera Mundi de J. de Sacrobosco. Veja-se Luís de Albuquerque - Os Guias Náuticos de Munique e Évora, Lisboa, J.I.U., 1965. 
rotas dos Oceanos Atlântico, Índico e Pacífico. Saber prático e utilitário fruta da investigação aplicada da revolução da náutica astronómica no Atlântico ou da recolha sistematizada de dados das náuticas asiáticas.

Os Roteiros de navegação oceânica, como a anónima Rota de Portugal para a Índia, de cerca de 1530 ou o Roteiro de Lisboa para a Índia de Diogo Afonso, de cerca de $1535^{27}$, são o corpo por excelência da náutica astronómica. Estas instruções para um caminho ideal nos mares assentam nos valores sistemático e controlado da latitude como elemento regulador decisivo da rota.

A cartografia é a representação parcial ou total da terra segundo uma escala mumericamente definida e determinadas convenções.

A cartografia portuguesa dos séculos XVI e XVII é formada por um conjunto de Cartas Náuticas de grande precisão nos complexos marítimos costeiros e com a máxima elucidação dos núcleos geográficos com importância para a navegação (cabos, baias, golfos, ilhas, portos).

Esta cartografia exprime a explosão informativa sobre a hidrografia e as massas litorais do planeta. Revolução informativa que é consequência da comunicação marítima, regular e continua, entre partes dos diferentes oceanos, continentes e civilizações.

A cartografia náutica portuguesa nasce nos meados do século $\mathrm{XV}$, a partir da herança mediterrânica da "carta-portulano" traçada de acordo com rumos magnéticos e distâncias estimadas, em ligação com a navegação astronómica. Por isso as cartas náuticas portuguesas são rumadas mas possuem uma ou mais escalas de latitudes..

Este compromisso da carta náutica rumada com as necessidades da náutica astronómica leva à graduação do equador, daí resultando uma nova espécie de carta rumada, com pequenos quadrados formados pelos paralelos e pelos meridianos.

A introdução das escalas de latitudes é a grande inovação técnica portuguesa na cartografia do século XVI. Existem ainda outras inovações portuguesas como, por exemplo, os planos hidrográficos com vistas de costas rebatidas no plano horizontal e o registo de sondas ${ }^{28}$.

Para além destas inovações técnicas, a cartografia náutica portuguesa

27 O primeiro dos Roteiros citado faz parte do Livro de Marinharia, Tratado da Agulha de Marear de João de Lisboa, ed. B. Rebello, Lisboa, L.Silva, 1903 e o segundo pode encontrar-se em A. Fontoura da Costa - Roteiros Portugueses Inéditos da Carreira da Índia do Século XVI, Lisboa, A.G.C., 1940, pg. 31-32. Veja-se Max Justo Gueses - A Carreira da ìndia - Evolução do seu Roteiro, Sep. Navigator, n. ${ }^{\circ} 20$, Rio de Janeiro, 1985

28 Veja-se Armando Cortesão - Cartografia e Cartógrafos Portugueses dos Séculos XV e XVI, Lisboa, S. Nova, 1935, 2 vols, e História da Cartografia Portuguesa, Lisboa, J.I.U., 1961-1971, 2 vols; A. Cortesão e A. Teixeira da Mota - Portugaliae Monimenta Cartographica, Lisboa, 1960, 6 vols; A. Pinheiro Marques - Origem e Desenvolvimento da Cartografia na Época dos Descobrimentos, Lisboa, I. Nacional, 1987. 
dos séculos XVI e XVII, é uma imensa revolução informativa sobre os espaços oceânicos e litorais nos mundos extra-europeus.

Esta revolucionária cartografia dos litorais africanos, americanos e asiáticos, em constante progressão, dos inícios do século XVI aos anos trinta do século XVII, resulta, quer da maior frequência das viagens marítimas e contactos mercantis e culturais dos portugueses, quer de ligações à marinharia e cartografia árabes, malaias, javanesas, chinesas e japonesas. Circulação de informação, sínteses e ligações alcançadas pela parceria económica local e pela miscigenação ${ }^{29}$.

Os Tratados Práticos de Construção Naval são conjuntos de modelos e de regras de saber fazer. Enunciados breves dos procedimentos adequados à boa produção da máquina por excelência do Renascimento Português que é o navio (caravela, nau, galeão) através de princípios gerais de natureza normativa e quantitativa ${ }^{30}$. Princípios de ordenação e de normalização técnico-prática que vemos, por exemplo, no anónimo Livro Náutico dos finais do século XVI, no Livro das Traças de Carpintaria, 1616 de Manuel Fernan$\operatorname{des}^{31}$, nas ainda inéditas "Regras Gerais para Navio" nas Curiosidades de Gonçalo de Sousa, que reúne materiais que vão de 1572 a 1635.

\section{V}

O campo teórico-crítico da cientificidade é formado por uma componente essencial de marinharia que designamos por Sabedoria do Mar e por uma componente quantitativamente secundária de Matéria Médica ${ }^{32}$ composta pelos Colóquios dos Simples e Drogas da Índia, Goa, 1563, de Garcia de Orta (1503-2563) e pelo Tratado de las Drogas Y Medicinas de las Indias Orientales, Burgos, 1578, de Cristóvão da Costa (c.1526-1593).

A Sabedoria do Mar é um conjunto de obras teóricas de marinharia,

29 Veja-se, por exemplo, Luís Filipe Barreto - Cartografia de Macau (Séculos XVI e XVII), Lisboa, M.M., Lisboa, 1997 e A. Pinheiro Marques - A Cartografia Portuguesa do Japão (Séculos XVI e XVII), Lisboa, I. Nacional, 1996.

30 Veja-se J.G.Pimentel Bararta - Introdução à Arqueologia Naval. Lisboa, C.E.M, 1973 e Estudos de Arqueologia Naval, Lisboa, I. Nacional, 1989, 2 vols, Luís Filipe Barreto - Os Navios dos Descobrimentos, Lisboa, Coorreios de Portugal, 1991; Quirino da Fonseca - A Caravela Portuguesa, Lisboa, M.M., 1978, 2 vols.

31 O Livro Náutico foi parcialmente publicado por Henrique Lopes de Mendonça Estudos sobre Navios Portugueses dos Séculos XV e XVI, Lisboa, A.R.Ciências, 1892 e a obra de Manuel Fernandes tem uma edição fac-similada do manuscrito, Lisboa, A.Marinha, 1989.

32 Sobre Garcia de Orta e Cristóvão da Costa, veja-se Luís Filipe Barreto Descobrimentos e Renascimento - Formas de ser e de pensar nos séculos XV e XVI, Lisboa, I. Nacional, 1982, pg. 255 a 295 e Caminhos do Saber no Renasco imento Português: Estudos de História e Teoria da Cultura, Lisboa, I. Nacional, 1986, pg. 109 a 201, bem como a bibliografia aí aindicada. 
ou seja, de náutica, de cartografia e de construção-arquitectura navais produzidas por Duarte Pacheco Pereira (c.1460-1533), D. João de Castro (1500-1548), Pedro Nunes (1502-1578) e Fernando Oliveira (1507$-1581 ?)$.

Muitos outros autores de uma forma pontual e externa comparticipam na Sabedoria do Mar, como vemos, por exemplo, no caso das críticas a Pedro Nunes, desenvolvidas, entre outros, pelo humanista Diogo de Sá no De Navigationi Libri Tres, Paris, 1549 e o cartógrafo André Homem, em correspondência dos anos de 1560. No entanto, os quatro autores apontados formam o núcleo da Sabedoria do Mar.

O campo teórico-crítico apresenta uma lógica de controvérsia frente a problemas deixados em aberto ou nem sequer abordados ao nível técnico, prático, empírico.

Na matéria médica trata-se de transcender acumulações informativas do tipo Roll de Çertas Drogarias, 1516, de Tomé Pires ou Informação de todas as Drogas que vão para o Reino, c.1545 de Simão Álvares. Transcendência do empírico através de uma investigação e descrição sistemáticas da farmacopeia asiática conhecida pelos europeus, de uma comparação exaustiva deste novo horizonte quinhentista com as heranças clássica, islâmica, medieval e também de digressões científico-filosóficas. Garcia de Orta e Cristóvão da Costa procuram assim fundamentar crítica e teoricamente, o novo horizonte à mão da medicina europeia.

A Sabedoria do Mar prolonga e transcende o mundo de temas e de problemas do campo técnico-prático. São então teorizadas, investigadas, crítica e sistematicamente, questões silenciadas ou simplificadas ao nível prático, como, por exemplo, a declinação magnética da agulha de marear, a tipologia de projecção cartográfica, a teoria das marés ou a questão da proporção entre terra e mar no todo do Globo.

A propósito destes e doutros problemas mais teóricos de marinharia, as quatro figuras essenciais da Sabedoria do Mar criam novos horizontes à ciência do Renascimento, abrem perspectivas de investigação triunfantes no futuro (casos do magnetismo terrestre ou da projecção Mercator) e levam à elaboração de uma filosofia da ciência em torno dos fundamentos do saber objectivo/verdadeiro a que chamamos Experiencialismo.

O Experiencialismo é uma teoria e metodologia do conhecimento verdadeiro fundada no princípio regulador da experiência como categoria nuclear de todo o programa do saber desde a origem à prova, desde a descrição à explicação fenomenais.

O Experiencialismo é, em si mesmo, uma controvérsia entre fundamentalmente duas vias. A via do experiencialismo como empiria sensorial frente à via do experiencialismo como racionalismo crítico-experiencial. Este combate de programas de conhecimento desenrola-se nos mundos da astronomia náutica, da representação cartográfica e da enge- 
nharia naval, ou seja, nos sectores chave da investigação científica e da tecnologia de ponta do Renascimento Português ${ }^{33}$.

O que separa os dois programas de experiencialismo é, antes de mais, o sentido atribuído por cada um ao conceito de experiência. Para o empirismo sensorial a experiência é: 1) vivência/acção individual de cada ser humano; 2) acumulação informativa de dados da realidade; 3 ) evidência da observação imediata e qualitativa. Pelo contrário, para o racionalismo experiencial, a experiência é: 1) observação quantitativa (maioritária) ou qualitativa (minoritária) repetida, comparada, pluripessoal e transmissível com fundamentação; 2) acumulação de dados da realidade que devem ser criticamente interrogados pois não constituem em si mesmo qualquer evidência ou certeza mas tão só uma recolha de quadro fenomenal; 3) acção especializada do ser humano no seu domínio de mundo e vida.

Entre o experiencialismo sensorial-empírico de um Duarte Pacheco Pereira e de um Fernando Oliveira e o experiencialismo crítico-racional de D. João de Castro e Pedro Nunes, encontramos uma oposição no conceito e na hierarquia de funções da experiência.

$\mathrm{O}$ experiencialismo no programa empirista sensorial absolutiza e centraliza a experiência. Toma os sentidos e a prática como concretização máxima da experiência e a observação qualitativa da natureza física ou humana, como uma resultante da vivência e da evidência. Tudo o mais, muito em especial a matemática e a razão teórica, aparece como oponente à transparência do experienciar empírico-sensorial.

O experiencialismo crítico-racional tende, pelo contrário, a complexificar a experiência. Não se trata de anular a experiência empírica e sensorial mas sim de a considerar tão só um nível elementar e dominado do problema.

A partir do jogo de oposições complementares entre experiência-razão-matemática, o racionalismo experiencial promove a observação mais quantitativa que qualitativa da natureza. A experiência torna-se observação provocada, repetida, controlada, calculada. Processo crítico e problemático destinado a transcender as transparências e os imediatismos empíricos.

O racionalismo experiencial de D. João de Castro e de Pedro Nunes considera a verdade como uma difícil e problemática conquista explicativa do real. Um processo aberto a múltiplos obstáculos e erros, entre eles, o da aparência sensorial que é necessário transcender através da coerência teórica (do tipo lógico-matemático) e da correspondência e coimplicação fenomenal enquanto observação instrumental quantitativa.

Os problemas colocados e resolvidos pelo experiencialismo da cultu-

33 Sobre esta controvérsia veja-se Luís Filipe Barreto - Os Descobrimentos e a Ordem do saber, Lisboa, Gradiva, 1987, pg. 55 a 97 e Experiência e Experiencialismo no renascimento Portugiês in Logos - Enciclopédia luso Brasileira de Filosofia, Lisboa, Verbo, 1990,pg. 407 a 415. 
ra da expansão representam uma forte crítica às metodologias dominantes no Renascimento. Críticas ao realismo empírico mas também às metodologias do Humanismo e da Escolástica, centradas no inquérito filológico e no princípio da autoridade hierárquica dos enunciados e dos grandes autores/autoridades.

\section{VI}

O campo geográfico-antropológico é composto por quatro grandes séries $^{34}$. A primeira, quantitativamente dominante mas qualitativamente a menos rica em informação e formulação, é a das Cartas-relatório. Cartas-relatório que são um sintético boletim informativo, local e pontual, muito ligado à situação institucional do Estado expansionista ou da Igreja missionária. A propósito de uma feitoria-fortaleza, de um negócio ou da vida de uma residência ou de um seminário surgem pontual e fragmentariamente alguns dados de natureza geográfica e antropológica sobre sociedades, paisagens e culturas de África, da Ásia ou do Brasil.

A segunda série, quantitativamente também a segunda mais frequente e em termos qualitativos a mais rica de informação e de formulação geográfico-antropológica é a dos Tratados. Tratados locais ou globais, sobre o homem e a natureza de partes de África, Ásia e América.

Estes Tratados são descritivas sistemáticas de aspectos das realidades natural e social. Assuntos abordados tanto no plano global, caso por exemplo de $O$ Livro das Cousas da India de Duarte Barbosa e da Suma Oriental de Tomé Pires, escritos entre 1511 e 1516, como no plano local com, por exemplo, a Relação de Bisnagar, c. 1518-1520, de Domingos Pais, que descreve o reino Hindu de Vijaynagar, os Tratados da Provincia do Brasil e da Terra do Brasil, de cerca de 1568-1570, de Pêro de Magalhães de Gandavo, o Tratado dos Rios de Guiné do Cabo Verde, de 1594, de André Álvares de Almada, a Relatione del Reame di Congo, Roma, 1591 de Duarte Lopes e F. Pigaffeta ou a Etiópia Oriental, Évora, 1609 de Frei João dos Santos ${ }^{35}$.

34 Para uma visão global sobre este universo de geografia descritiva e antropológica, veja-se Luís Filipe Barreto - A Ordem do Saber na Antropologia dos Descobrimentos Portugueses in autores vários - A Ciência e os Descobrimentos, Lisboa, JNICT, 1996, pg. 25 a 67; H. Cidade - A Literatura Portuguesa e a Expansão Ultramarina, Coimbra, A. Amado, 1963-1964, 2 vols: J. Castro Osório - O Além-Mar na Literatura Portuguesa, Lisboa, Gama, 1948.

35 Sobre estas geografias antropológicas em relação à Ásia e Brasil veja-se Luís de Albuquerque, A L. Ferronha, J. S. Horta e R. Loureiro O Confronto do Olhar, Lisboa, Caminho, 1991 e Luís Filipe Barreto - O Brasil e o Indio na Geografia dos Descobrimentos Portugueses-Século XVI, Sep. Revista da UNL, Lisboa, 1992-1993 e Lavrar o Mar: os Portugueses e a Ásia, Lisboa, CNCDP, 2000, pg. 61 a 97; José da Silva Horta - A Representação do Africano na Literatura de Viagens, do Senegal à 
Rico e imenso comjunto de obras que pode tomar mil e uma formas que vão desde o organização conjunta de tratados descritivos global e local, natural e social, como vemos, por exemplo, em 1587, com Gabriel Soares de Sousa e a sua Notícia do Brasil. Descrição verdadeira da costa daquele estado que pertence à Coroa do Reino de Portugal, sítio da Baia de todos os santos e fertilidade daquela provincia, com relação de todas as aves animais, peixes, bichos e costumes dos gentios muito certa e curiosa. Até, pelo contrário, à especialização local natural ou local antropológica como surge no jesuíta Fernão Cardim, em 1584, com respectivamente, Do Clima e Terra do Brasil e Do Princípio e Origem dos Índios do Brasil e de seus costumes, adoração e cerimónias ${ }^{36}$.

Pluralidade destes Tratados descritivos que pode mesmo tomar a forma de inventário de contrastes e de diferenças frente à condição europeia, como é o caso do Tratado...contradições e costumes entre a gente de Europa e esta província de Japão, 1585 de Luis Fróis, S.J. ou enveredar pela exposição especializada da espiritualidade, neste caso indiana, como vemos com o Tratado sobre o Hinduismo, c. 1616 de Gonçalo Fernandes Trancoso, S. J e o Tratado dos Deuses Gentilicos c.1618, de Manuel Barradas, S.J.

A terceira série é composta pelos Vocabulários, Gramáticas, Dicionários de línguas de África, Ásia e América ${ }^{37}$. Nos inícios, recolha breve e pontual de algumas palavras para o dia a dia, em especial mercantil, como logo vemos no Vocabulário Malaiala que acompanha o relato da primeira viagem de Vasco da Gama à Índia em 1497-1499.

A partir de meados de Quinhentos é toda uma investigação sistemática que surge, por exemplo, nas obras de Henrique Henriques S.J, (1520-1600), Arte da Gramática da Língua Malabar, c. 1561 e Vocabulário da Lingua Malabar, c. 1570, na Arte Tamulica-Portuguesa, c. 1560 de Baltazar da Costa S.J. (1538-1580), no Vocabulário da Lingua Brasilica, c. 1570 de Leonardo do Vale S.J. (1538-1591), na Arte de Grammatica da lingua mais usada na costa do Brasil, Coimbra, 1595 de José de Anchieta S.J. (1534-1597, na Arte da Língua Brasilica, Lisboa 1621 de Luis Figueira S.J. (c.1574-1643).

Serra Leoa (1453-1508), Sep. de Mare Liberum, n 2, Lisboa, 1991, pg. 209 a 339 e $O$ Africano: Produção Textual e Representações (Séculos XV-XVII) in Condicionantes Culturais da Literatura de Viagens, ed. F. Cristóvão, Lisboa, Cosmos, 1999, pg. 262 a 301; Guilhermo Glucci - Sem Fé, Lei ou Rei: Brasil 1500-1532, Rio de Janeiro, Rocco, 1993; W.G.L.Randles - L`Image du Sud-Est African dans la Littérature Européenne au XVI Siècle, Lisboa, C.E.H.U., 1959.

36 Veja-se a recente edição de Fernão Cardim - Tratados da Terra e Gente do Brasil, ed. Ana Maria Azevedo, Lisboa, CNCDP, 1997.

37 Veja-se, entre outros, David Lopes - Expansão da Língua Portuguesa no Oriente nos Séculos XVI, XVII, XVIII, Porto, Portucalense, 1969. 
Os mesmos resultados são alcançados para as grandes línguas da Ásia Oriental, desde o colectivo Dicionário Português-Chinês, nascido em Macau, nos anos de 1580-1582, até aos Dicionários dos anos de 1620-1630, Português-Vietnamita, de António Barbosa S.J e Vietnamita-Português de Gaspar do Amaral S.J. (1595-1645), passando pelo Dictionarium Latino Lusitanium ac Iaponium, Amacusa, 1595, o Vocabulário da Lingua de Iapan, Nagasaqui, 1603-1604 ou a Arte da Lingua de Iapam, Nagasaqui, 1604-1608 e a Arte Breve da Lingua Iapoa, Macau, 1620, ambos de João Rodrigues S.J. (1561-1633).

Estudo sistemático das línguas desenvolvido pelos missionários, em especial jesuítas. Estudo directamente implicado à missionação que leva ao aparecimento de extensões desta série como no caso dos Catecismos em Tamil por Henrique Henriques S.J., em Coulão, 1576; em chinês, nos anos de 1581-1582, em Macau; em língua japonesa, em Nagasaqui, 1600 e na língua tupi de Marcos Jorge S.J. e de Leonardo do Vale S.J. que data de cerca de 1574, Doutrina cristã na lingua do Brasil.

Exercícios de tradução que não se restringem à cultura cristã e envolvem as culturas clássica e moderna. O Tratado de Lógica/Ming Li Tam, de Aristóteles surge em Gangzhou, 1631, traduzido por Francisco Furtado S.J. (1587-1653), responsável pela edição chinesa em 10 volumes de Cursus Conimbricensis. O Tratado de Astronomia/Tian Wen Lue de Manuel Dias S.J. (1574-1659), Beijing, 1615 é a primeira obra em chinês a apresentar o telescópio.

Traduções não apenas do português e do latim para línguas não europeias, mas também dessas mesmas línguas para o universo cultural europeu. Em Macau, nos anos de 1581-1582 uma equipe coordenada por M. Ruggieri inicia a tradução para latim do Da Xuel O Grande Ensinamento de Confúcio (551-479 AC). A segunda tradução desta obra do mandarim para latim, começada por volta dos anos de 1630 , é da autoria de Inácio da Costa S. J. (1603-1666), Sapientia Sinica, Paris, 1662. Dos mesmos anos de 1630 são as traduções para português de literatura indiana por Francisco Garcia S.J. (1580-1659) O Homem das Trinta e duas Perfeições e Outras Histórias.

A quarta série é a dos Relatos de viagem terrestre e marítima. Narrativas e descritivas de passagem que vão sumariando dados geográfico-antropológicos, como vemos no caso da Verdadeira Informação das Terras do Preste João das Índias, Lisboa, 1540, de Francisco Álvares, no Relato da Navegação e do litoral do Brasil, dos anos de 1530-1532, de Pêro Lopes de Sousa ou nas Cartas do Novo Descobrimento do Gram Catayo-Tibete, de 1624-1626, de António de Andrade S.J38.

38 Veja-se, por exemplo, J.N. Carreira - Do Preste João às ruínas do oriente, Lisboa, E-América, 1997; Luís Graça - A Visão do Oriente na Literatura Portuguesa de Viagens: Os Viajantes Portugueses e os Itinerários Terrestres (1560-1570), Lisboa, I. Nacional, 1983. 


\section{VII}

O campo doutrinário-ideológico é o lugar do encontro e da transição entre a cultura da expansão e as culturas humanista, escolástica e popular sobre a expansão. Espaço ideológico e doutrinário que encontra o seu mundo de temas e de problemas no valor e no sentido da Expansão e da presença portuguesas no mundo ${ }^{39}$.

Estes discursos são legitimações, elucidações. interrogações e críticas em torno da Diáspora enquanto Mundo de Valores. Elementos que surgem nos mais diferentes tipos de discurso através de três formas dominantes: Dispersão, Autorização e Concentração.

$\mathrm{Na}$ Dispersão o juízo em torno da diáspora surge pontual e fragmentariamente, no interior de discursos externos ao horizonte cultural da expansão.'É, por exemplo, o que acontece na Comédia Eufrosina, Coimbra, 1555, de Jorge Ferreira de Vasconcelos onde o fenómeno da mercantilização é oposto à tradicional guerra santa e justa e onde a crescente mercantilização dos portugueses na Ásia surge como decadência universal, "também Portugal dessa maneira é Índia" são as palavras de J.F. de Vasconcelos.

O mesmo se encontra na primeira História de Portugal ${ }^{40}$ escrita por Fernando Oliveira, cerca de 1581. Este panfleto independentista em torno do Portugal antigo e medieval acaba por mencionar a China e o Japão, a Guiné e o Brasil, como prova do limitado poder imperial romano. Ou, na Chorographia, Coimbra, 1561, de Gaspar Barreiros, uma obra descritiva de uma viagem por terra a Itália. O tema da expansão surge pontualmente, quer como positivo fenómeno de mundialização do cristianismo, quer como negativa pobreza produtiva devido à sede da conquista das riquezas alheias.

A Autorização surge nos discursos políticos, jurídicos, e, acima de tudo, na historiografia. A história da diáspora representa cerca de $60 \%$ da historiografia portuguesa de Quinhentos.

Estas histórias humanistas, de forma exemplar, apresentam récitas dos acontecimentos da expansão portuguesa em implicação com normas e valores sobre a origem e o sentido da diáspora, como vemos nas obras de, entre outros, Gomes Eanes de Zurara (c.1410-1474), Gaspar Correia (c.1490-c.1563), Fernão Lopes de Castanheda (c.1514-1559), João de Barros (1496-1570), Damião de Góis (1502-1574), Diogo do Couto (1542-1616).

39 Para uma visão global do problema, veja-se Maria Leonor Garcia Cruz - Os "Fumos da Índia": Uma Leitura Crítica da Expansão Portuguesa, Lisboa, Cosmos, 1998.

40 Editada recentemente por José Eduardo Franco: O Mito de Portugal: A Primeira História de Portugal e a sua Função Política, Lisboa, Roma Editora, 2000. 
A concentração leva ao aparecimento de autênticas teses sistemáticas sobre o sentido e o valor da expansão. Teses de doutrina literária como os Lusíadas, Lisboa, 1572, de Luís de Camões ${ }^{41}$ e a Peregrinação, Lisboa, 1614, de Fernão Mendes Pinto ou de doutrina política objectiva como os dois Diálogos do Soldado Prático, de Diogo do Couto ${ }^{42}$, o primeiro provavelmente escrito cerca de 1555-1574 e o segundo por volta de 1611-1612, o anónimo Primor e Honra da Vida Soldadesca no Estado da Índia, impresso em Lisboa, 1630 ou a Reformação da Milicia e Governo do Estado da Índia Oriental de Francisco Rodrigues Silveira (c.1558-c.1640), com seis redacções manuscritas entre 1599 e $1622^{43}$.

O campo doutrinário-ideológico apresenta três grandes constantes. A primeira vê a expansão portuguesa a partir de um quadro teológico e transcendental. A diáspora marítimo-mercantil sofre uma redução e consagração à ideia da Cidade de Deus. Os portugueses em diáspora surgem como instrumento de acção divina no mundo, o povo eleito do cristianismo moderno e planetário 44 .

A segunda constante, em estreita articulação com este ideal de religiosidade, faz a propaganda e o elogio do valor político-militar da expansão. A guerra santa e justa é uma demonstração dos poderes de Portugal e da Cristandade.

A terceira constante afirma a novidade dos tempos e dos mundos trazida pela expansão marítima e mercantil dos portugueses. É a propósito deste tópico da novidade que melhor surge a ambivalência da doutrina da expansão. No plano do conhecimento toma-se como positiva esta novidade, mas a nível do acontecimento, do comportamento, dos valores éticos e do trabalho, esta novidade é, na maior parte dos casos, julgada como profundamente negativa ${ }^{45}$.

\section{VIII}

A cultura da expansão portuguesa contribui para o Renascimento Europeu através de vários elementos chave. Antes de mais, esta cultura

41 Veja-se Martin de Albuquerque - A Expressão do Poder em Luís de Camões, Lisboa, I. Nacional, 1988 e J. Borges de Macedo - Os Lusíadas e a História, Lisboa, Verbo, 1979.

42 Veja-se A. Coimbra Martins - Em Torno de Diogo do Couto, Coimbra, B. Geral, 1985.

43 Francisco Rodrigues Silveira - Reformação da Milicia e Governo do Estado da Índia Oriental, ed. B.N. Teensma, G. Winius e L.F. Barreto, Lisboa, F. Oriente, 1996.

44 Veja-se A. Sousa Costa - O factor Religioso, Razão dos Descobrimentos Portugueses in (Actas) Congresso Internacional de História dos Descobrimentos, Lisboa, 1961, vol. IV. Pg. 99 a 138.

45 Veja-se Luís de Matos - Os Descobrimentos Portugueses - O Começo da Cultura Moderna: Inovação e Mudança in Reflexões sobre História e Cultura Portuguesa, Coord. M.C. Ferreira, Lisboa, IPED, 1985, pg. 75 a 134. 
portuguesa torna-se o mensageiro por excelência do Mundo Renascentista. O notícias do Mundo na Europa e o noticiário da Europa no resto do Mundo.

A cultuta da expansão portuguesa, nos mares e litorais de África, da Ásia e da América, é o intermediário intercultural mais relevante entre os finais do século XV e os anos de 1620-1630.

Ligada a esta dimensão de informador e de tradutor Europa-Mundo surge a revolução informativa à escala planetária. Graças a esta rede marítimo-mercantil, regular e contínua, dá-se uma explosão informativa sobre o homem e a natureza à escala planetária. Pela primeira vez, círculos de elite cultural europeia possuem uma imagem e comunicação global do mundo. Um banco de dados variado e cada vez mais fundamentado que permite à Europa o poder de classificar, nomear, comparar, a realidade dos Mundos do Mundo.

Um outro elemento decisivo da cultura da expansão é o acelerado desenvolvimento de certas áreas técnico-científicas. Desenvolvimento empírico e limitado, mas mesmo assim, relevante desenvolvimento no mundo de Quinhentos, de áreas como a astronomia e a cartografia náuticas, a construção naval e militar, a botânica médica, a hidrografia, a geografia e a antropologia.

A cultura da expansão portuguesa contribui também para a crítica racional, sistemática e fundamentada de parte das heranças culturais europeias. Em especial a nível informativo, a cultura da expansão funciona como martelo crítico e interrogativo de muitos princípios e horizontes nucleares do conhecimento herdado da Antiguidade Clássia e da Medievalidade. Heranças que podem agora, no século XVI, com a cultura da expansão, serem parcialmente recusadas ou pontualmente aceites a partir de critérios fundados na observação, comparação, razão crítica e experiencial e não no critério mais tradicional, as autoridades.

É no entanto necessário ver que estes contributos ganham forma e sentido no interior de um humus assente em fortes heranças. A novidade cultural da Expansão vive num limite de tanta ou mais continuidade que descontinuidade.

Recolocar o universo cultural da Expansão Portuguesa no horizonte epocal que o fez nascer e viu viver implica situar a cultura da diáspora num horizonte regulado pela síntese aristotélico-tomista e dominado por elementos de aristotelismo naturalista e renascentista.

O Mundo e a Natureza da Expansão operam com uma física essencialmente orgânica e qualitativa e com uma epistemologia aristotélica e naturalista. As palavras de ordem ecoam a partir da Antiguidade clássica greco-romana: “...todos os homens desejam naturalmente saber" (Aristóteles -Metafísica, A,I,980 a 21) através da medievalidade cristã (“...todo o homem deseja naturalmente conhecer..." T. Kempis - Imita- 
ção de Cristo, II,1) para formar enunciados chave de Quinhentos:"...naturalmente os homens desejam saber..."46.

A Cultura da Expansão emerge e ganha sentido no interior de uma física aristotélica, de uma astronomia ptolomaico-geocêntrica, de uma medicina galénica, de uma farmacopeia fundada na tradicional lógica classificativa de Dioscórides, de uma história natural orientada por Aristóteles e Plínio, de uma geografia onde pontificam Ptolomeu e Plínio, de uma história moral centrada nas heranças da Ética e da Política aristotélicas, bem como na reflexão cristã de S. Agostinho e de S. Tomás de Aquino.

O universo cultural da Expansão usa estas heranças como utensilagem reguladora do classificar, descrever, explicar. Utilização da herança através de escolhas e adaptações às novas realidades e necessidade, tradição retocada que é o humus da invenção.

A Cultura da Expansão é em muitos aspectos fundamentais tradição retocada e melhorada. A náutica astronómica é uma revolução nas formas de navegar mas é ao mesmo tempo também tradição retocada com o uso e a adaptação do astrolábio que faz surgir o astrolábio náutico. Do mesmo modo a cartografia náutica é uma renovação do saber mas é também, ao mesmo tempo, a fusão criativa de duas heranças até aí divergentes: a Carta Portulano de Rumos e a Escala de Latitudes da cartografia Ptolomaica.

Em grande medida a renovação dos saberes técnicos e científicos da Cultura da Expansão resulta de quadros antigos, quando olhados separadamente, mas de uma alta novidade quando reparamos na sua combinação e nas resultantes e desenvolvimentos alcançados a partir desta arte de combinar e de potenciar o mundo tradicional orgânico e qualitativo.

A adaptação e a fusão criativas de heranças e de novos horizontes de saber extra europeu potencia uma limitada mas relevante inovação. A tradição retocada e melhorada não impede a crítica ao herdado e normalizado como verdade ${ }^{47}$.

A crítica das heranças clássica e medieval, sobretudo no plano informativo, não é jamais crítica de destruição do essencial herdado e muito menos criação de alternativa ao paradigma orgânico e qualitativo.

Crítica de correcção, de confrontação, de elucidação que faz parte do

46 A Summa Oriental de Tomé Pires e o Livro de Francisco Rodrigues, ed. A. Cortesão, Coimbra, I. Universidade, 1978, pg. 129.

47 “...estiverão commumente os antigos muy quietos nesta opinião em quanto cuidarão que não avia, nem podia aver mais terras descubertas dagoa, que as que conhecerão de África, Asia, Europa, nas quaes tres partes escassamente achavão a metade deste nosso hemispherio da terra descuberto dagoa... in D. João de Castro - Tratado da Sphaera, por perguntas e respostas a Modo de Diálogo, c. 1535, Obras Completas, ed. A. Cortesão e L. Albuquerque, Coimbra, A.I.C.P., 1968, vol. I, pg. 49. 
retocar da herança para uma melhor utilização da mesma, como vemos na crítica às limitações e aos erros das "Tábuas Ptolomaicas" que coexiste com o seu uso prático retocado e com a aceitação do geocentrismo ptolomaico: “... e por tanto quê entende os discursos de Ptolomeo entêdera quâ pouca certeza pode aver nos sitios dos lugares q com suas tavoas pôe..." 48 .

A Cultura da Expansão contribui, com os seus horizontes de adaptação e de revolução informativa e prática, para um alcançar das potencialidades do tradicional mundo orgânico e qualitativo. Mas, ao mesmo tempo, contribui para o esgotamento e o enfraquecimento desse mesmo mundo tornando mais patente o facto de que no Renascimento "...uma ordem declina sem que ainda se tenha formado uma nova ordem..."

\section{RÉSUMÉ}

\section{FONDEMENTS DE LA CULTURE PORTUGAISE DES DÉCOUVERTES}

Ce bref article se donne comme but de présenter une introduction à la culture portugaise des Découvertes, laquelle représente une des manifestations par excellence da la Renaissance portugaise. On commence par intégrer cette culture dans le cadre des programmes intellectuels et savants de l'époque, pour suivre ensuite les caractéristiques, les oeuvres et les figures des différents champs discursifs où elle se déploie. Finalement, on cherche à évaluer la culture portugaise de la période qui va du milieu du XV.ème au début du XVII.ème siècle à la lumière des réseaux de continuité et de discontinuité de ce temps qui l'a vu naître et se développer.

48 Pedro Nunes - Livro Primeiro da Geografia de Ptolomeu, Lisboa, 1537, Obras, Lisboa, A.C.L., 1940, vol.I, pg. 155.

49 Eugenio Garin - Sciencia e Vita Civile nel Rinascimento Italiano, Bari, Laterza, 1965, pg. 12. 